\section{Endoscopic retrograde cholangiopancreatography stents: indications, risks and novel uses}

\section{Neville Azzopardi \\ Gastroenterology Department, Mater dei Hospital, Tal Qroqq, Malta}

\section{Abstract}

Stents cannulating the common bile duct and/or the pancreatic duct are frequently used during endoscopic retrograde cholangiopancreatography in both temporary and definitive management of several conditions. While plastic stents have a high risk of occlusion within a few months, metal stents have larger diameters and may, therefore, last longer. However, they tend to have a higher initial cost and once placed, tend to be more difficult to manipulate or remove. Emerging data are now showing that the removal of covered self-expandable metal stents can be achieved relatively easily without the risks of major complications. This review article investigates the indications and complications for stent insertion, as well as the recommended type of stent for each indication.

\section{Introduction}

Endoscopic retrograde cholangiopancreatography (ERCP) is a valuable tool in the management of hepatobiliary diseases. Stents cannulating the common bile duct (CBD) and/or the pancreatic duct (PD) are frequently used during ERCP in the temporary and definitive management of several conditions. In this review article, we review the indications, risks and novel uses of stents during ERCPs.

The stents used during ERCP can be either plastic or metal. While plastic stents have a high risk of occlusion within a few months, metal stents have larger diameters and may, therefore, last longer. However, they tend to have a higher initial cost and once placed, tend to be more difficult to manipulate or remove. ${ }^{1}$

Emerging data are now showing that the removal of covered self-expandable metal stents (CSEMS) can be achieved relatively easily without the risks of major complications. In an analysis on the safety and outcome of removal of fully covered SEMS during ERCP, Kasher et al. showed that all 37 stent removal attempts were successfully achieved without difficulty. ${ }^{2}$ Indwelling stent-related complications occurred in 4 of 37 patients, including secondary strictures in 3 and a minor biliary leak in one. Two of 3 secondary strictures occurred at the distal stent margin of oversized intraductal stents, and another stricture occurred at a proximal stent margin of an oversized transpapillary stent. All of these cases were treated successfully with repeat stenting and resolved without further sequelae.

The main indications for the insertion of stents during ERCP are shown in Table 1.

\section{Materials}

A Pubmed search was made using the terms ERCP stents AND cholangiocarcinoma AND pancreatic carcinoma AND ampullary carcinoma AND common bile duct obstruction. Over 38,000 Pubmed results were obtained and these were reviewed specifically for any reference to common bile duct stents or pancreatic duct stents inserted during ERCP. In particular, the search results were narrowed down to 323 articles dealing with endoscopic treatment and ERCP stenting of the biliary obstruction. These articles were further narrowed down to those dealing with the current recommendations and novel research on ERCP stents.

\section{Cholangiocarcinoma}

ERCP is a useful tool in the diagnosis and management of cholangiocarcinomas. ${ }^{3}$ On cholangiography, the appearance of a stricture can suggest malignancy, although this is inconclusive. Tissue for cytology during ERCP can be obtained by brushing, biopsy and bile aspiration, although in most cases brush cytology tends to have a low sensitivity (18-60\%). ${ }^{4}$ Cholangiocarcinoma has a dismal prognosis with an average 5 -year survival of $5-10 \% .^{5}$ The only curative therapy is surgical resection. Patients undergoing surgical resection have a median survival of 37.2-42.9 months while those not fit for surgical resection have a median survival of 6.7-11.6 months. ${ }^{6}$ Surgery offers a cure for the minority of patients with cholangiocarcinoma, with a 9-18\% 5-year survival for proximal bile duct lesions and 20-30\% 5 -year survival for distal lesions. ${ }^{7}$ Only $10-20 \%$ of patients with cholangiocarcinomas are candidates for surgery.

In patients with unresectable disease, biliary decompression for palliative purposes can be accomplished surgically, radiologically or endoscopically with endoscopic decompression being the preferred option. Only $25 \%$ of the liver needs to be adequately drained to relieve jaundice and provide palliation. Therefore, in strictures affecting both left and right hila, unilateral stenting of only one duct system is necessary. In a randomized controlled prospective trial, De Palma et al. ${ }^{8}$ evaluated 157 patients with malignant hilar biliary obstruction due to cholangiocarcinoma, gallbladder cancer or periportal metastatic lymphadenopathy. In patients with unilateral stenting, there
Correspondence: Neville Azzopardi, Gastroenterology Department, Mater dei Hospital, Tal Qroqq MSD 137, Malta. Tel. 356.99853695.

E-mail: oldcharm@onvol.net

Key words: ERCP stent, covered self-expandable metal stent, plastic stent, post-ERCP pancreatitis, cholangiocarcinoma.

Conflict of interests: the author reports no potential conflict of interests.

Received for publication: 30 0ctober 2011.

Revision received: 22 February 2012.

Accepted for publication: 1 March 2012.

This work is licensed under a Creative Commons Attribution NonCommercial 3.0 License (CC BYNC 3.0).

(C) Copyright N. Azzopardi, 2012

Licensee PAGEPress, Italy

Gastroenterology Insights 2012; 4:e12

doi:10.4081/gi.2012.e12

was a higher success rate for stent insertion ( $89 \%$ vs $77 \%$ ) and drainage ( $81 \%$ vs $73 \%$ ) and, therefore, a lower early complication rate $(19 \%$ vs $27 \%$ ) when compared to bilateral stenting of both hepatic lobes. Early complications included cholangitis and stent occlusion. No differences were found in survival or procedurerelated mortality.

Both plastic (polyethylene) and metal biliary stents are available for use in cholangiocarcinomas. Numerous studies have compared costs, complications and survival with both types of stents. ${ }^{9-11}$ There are no differences in survival with the use of either stents. Plastic stents tend to occlude earlier and more frequently with $30 \%$ occlusion rates after three months and $70 \%$ after six months. ${ }^{11}$ It is, therefore, recommended to change plastic stents every three months in order to prevent occlusion and cholangitis.

Metal stents have a longer patency of approximately 12 months since they have larger diameters than plastic stents (10 mm vs 3.8 $\mathrm{mm}) .{ }^{7}$ However, as outlined above, once placed they can be difficult to manipulate or remove. Additionally, the initial cost of a metal biliary stent is higher, though with plastic stents there are subsequent costs due to the need for repeat procedures for stent replacement and increased hospitalization for complications. Overall, there is no significant difference in the cost between metal and plastic stents, though metal stents may be associated with reduced hospital stay overall.

Tumor overgrowth through the mesh of metal stents may lead to further problems with biliary obstruction and sepsis. This may be overcome by inserting plastic stents through 
the lumen of the metal stent, which appears to be more cost-effective, or placement of a further mesh metal stent where technically possible. ${ }^{11-14}$

The decision as to whether to use a plastic or metal stent will frequently depend on the patients' overall health, expected length of survival, quality of life and local expertise. Often, a plastic stent is placed initially while further diagnostic workup is underway. Once the diagnosis has been made, and the patient has confirmed unresectable disease and a life expectancy of more than six months, then the plastic stent can be replaced with a metal stent. Placement of a metal stent eliminates the need for repeat procedures and their associated risks.

The controversy over whether and how to perform pre-operative biliary drainage in patients with hilar cholangiocarcinoma continues. The British Society of Gastroenterology guidelines for the diagnosis and treatment of cholangiocarcinoma ${ }^{7}$ recommend that stents should ideally not be inserted before assessing resectability. A biliary stent may make it difficult to assess the proximal extent of the tumor intraoperatively and may increase the risk of infections postoperatively. However, elevated bilirubin levels and liver dysfunction are factors that adversely affect postoperative morbidity. Indications for biliary stent placement preoperatively include acute suppurative cholangitis or prevention of cholangitis after a diagnostic ERCP is performed or if surgery is to be delayed for an extended period of time. Preoperative drainage may also be beneficial in certain patients who are severely malnourished or as a technical aid in patients requiring a difficult hilar dissection for proximal biliary diseases. ${ }^{15-16}$

Pre-operative intrahepatic segmental cholangitis is a major prognostic factor in the outcome of major hepatectomy for biliary cancer. ${ }^{17}$ In addition, in patients undergoing liver resection for hilar cholangiocarcinoma, future liver remnant volume of less than $30 \%$ of total liver volume is associated with increased risk for hepatic insufficiency and death. Pre-operative biliary drainage of the future liver remnant appears to improve outcome if the predicted volume is less than $30 \%$. However, in patients with future liver remnant volume of $30 \%$ or more, pre-operative biliary drainage does not appear to improve perioperative outcome. ${ }^{18}$

Accordingly, no randomized controlled trials (RCTs) have been performed to clarify the safety of major hepatectomy for cholestatic patients with hilar cholangiocarcinoma. The danger of obstructive jaundice increasing the risk of infection have only been revealed in experimental studies. ${ }^{19-21}$ Therefore, many eastern hepatobiliary surgeons believe that biliary drainage is mandatory if major hepate-

Table 1. Indications for stent insertion during endoscopic retrograde cholangiopancreatography.

Cholangiocarcinoma with biliary obstruction

Pancreatic carcinoma with biliary obstruction

Ampullary carcinoma undergoing endoscopic resection

Benign biliary strictures

Primary sclerosing cholangitis

Sphincter of Oddi dysfunction

Large or multiple common bile duct stones not retrieved during ERCP

Chronic pancreatitis with / without pancreatic duct stones

Pancreatic strictures

Pancreatic duct leaks

Post-ERCP pancreatitis prophylaxis

Post-cholecystectomy biliary injuries

ERCP, endoscopic retrograde cholangiopancreatography.

ctomy for patients with hilar cholangiocarcinoma is to be safe. ${ }^{22-25}$ Experimental studies have revealed that pre-operative internal biliary drainage is superior to external drainage in liver regeneration and function after hepatectomy in obstructive jaundice..$^{26-27}$

No definite criteria or guidelines outlining indications for pre-operative biliary drainage are currently available. In patients with hilar cholangiocarcinoma, pre-operative biliary drainage may be performed by either percutaneous transhepatic biliary drainage or endoscopic biliary drainage. No consensus, however, has been reached regarding which method is more appropriate. No reported study has compared the effectiveness of percutaneous transhepatic biliary drainage, endoscopic biliary stenting, and endoscopic nasobiliary drainage in patients with cholangiocarcinoma. ${ }^{28}$

Arguments against pre-operative biliary drainage before pancreatoduodenectomy have recently been gaining momentum. ${ }^{29}$ Three RCTs have revealed that pre-operative percutaneous transhepatic biliary drainage does not improve perioperative results. ${ }^{30-32}$ However, these studies included a considerable number of patients undergoing palliative surgery and a small number undergoing major surgery. In another RCT, pre-operative endoscopic biliary drainage for malignant obstructive jaundice was shown to have no demonstrable benefit. ${ }^{33}$

In a randomized trial comparing uncovered and partially covered self-expandable metal stents in the palliation of distal malignant biliary obstruction, there was no significant difference in time to recurrent biliary obstruction or patient survival between the partially covered and uncovered SEMS groups. Partially covered SEMSs were associated with more serious adverse events, particularly migration. ${ }^{34}$ Similarly, there were no significant differences in stent patency time, patient survival time or complication rates between covered and uncovered nitinol metal stents in the palliative treatment of malignant distal bil- iary obstruction. However, covered stents migrated significantly more often compared with uncovered stents, and tumor ingrowth was more frequent in uncovered stents. ${ }^{35,36}$ RCTs comparing covered to uncovered stents in patients with unresectable distal biliary malignancies showed that the patency of covered stents was significantly higher than that of uncovered stents. ${ }^{37}$ However, many studies report an increased risk of cholecystitis (5\%) with the covered stents due to cystic duct occlusion. ${ }^{37,38}$

One of the problems in endoscopic placement of multiple plastic biliary stents is proximal dislocation of the first stent at the time of subsequent stent insertions. A proximally dislocated stent above the papilla may be very difficult to remove. Endoscopists from Tokyo, Japan have reported a technique called the anchor-wire technique, useful for preventing proximal dislocation of proximal biliary stents in endoscopic placement of multiple stents. ${ }^{39}$ To prevent proximal dislocation of the first stent into the bile duct, a stiff guidewire is inserted from the distal end of the first stent through the distal side hole, leading it towards the third portion of the duodenum and making it work as an anchor-wire. Upon inserting the second biliary stent, the anchor-wire successfully prevents proximal dislocation of the first stent inclined to migrate into the bile duct, by pulling it down.

Antibiotic prophylaxis should be given routinely in patients with hilar cholangiocarcinoma in whom it can be anticipated that complete biliary drainage will be difficult or impossible to achieve during one procedure. Patients presenting with bacterial cholangitis should already be established on antibiotics at the time of ERCP. The preferred antibiotic is frequently ciprofloxacin (750 mg orally $60-90 \mathrm{~min}$ before the procedure) or gentamicin (1.5 $\mathrm{mg} / \mathrm{kg}$ intravenously over 2-3 min). ${ }^{40}$ 


\section{Pancreatic carcinoma}

Common bile duct stents are frequently used to endoscopically decompress the biliary system in malignant pancreatic head cancer. It was unclear whether plastic or metal stents were more suitable for pre-operative biliary decompression in pancreatic cancer, but new data now show SEMS to be superior to plastic stents. ${ }^{41,42}$ In patients undergoing neoadjuvant chemoradiotherapy, plastic biliary stents do not maintain patency long enough to complete the treatment. Placement of SEMS appears to give safe and efficacious palliation for biliary and duodenal obstruction due to unresectable pancreatic head carcinoma. The majority of patients do not require further intervention and those who do can usually be managed without surgery. ${ }^{43-44}$

The presence of distant metastases was identified as the only independent prognostic factor for survival after initial biliary drainage. An SEMS should be systematically chosen for patients without distant metastases (median survival 6.6 months), whereas polyethylene plastic stents should be preferred in patients with distant metastases (median survival 3.1 months). ${ }^{45}$ There appears to be no difference in efficacy, duration of stent patency, occlusion rates and complications between the nitinol and the stainless steel uncovered metal stents. ${ }^{46}$ With the use of chemotherapy, patients who are palliated with metal stents are now surviving longer, and these long-term survivors with metal stents have been shown to have greater odds of developing cholangitis (11.5\% for those surviving one year or under compared to $46.5 \%$ surviving more than one year) ${ }^{47}$ Retrospective analysis has also shown a higher risk of post-ERCP pancreatitis for malignant biliary obstruction with metal stents when compared to plastic stents with no significant difference between covered and uncovered stents. ${ }^{48}$ Duodenal invasion is a risk factor for early self-expandable metal stent dysfunction in patients with pancreatic cancer. ${ }^{49}$

Pre-operative biliary drainage before surgery for cancer of the pancreatic head does not appear to affect survival rate. ${ }^{50}$ However, cholangitis remains a formal indication for early, urgent pre-operative biliary decompression for patients with pancreatic cancer. ${ }^{51}$

The application of endobiliary SEMS is considered the palliative treatment of choice in patients with biliary obstruction in the setting of inoperable malignancies. In the presence of SEMS, however, radical surgery is the only curative option when the resectability status is revised in case of malignancies. Revising the initial palliative approach and operating in the setting of biliary metallic stents is extremely demanding and carries significant mortality and morbidity. Radical resection is the only option for offering cure in such complex cases, and this should only be attempted in advanced hepatopancreaticobiliary centers with active involvement in liver transplantation. ${ }^{52}$

Other authors ${ }^{53}$ recommend that the placement of the newly available CSEMS can be used to effectively and safely treat biliary obstructions from pancreatic carcinoma and as an initial intervention to relieve malignant biliary obstruction, even in patients whose surgical resectability status is uncertain. Stenting of biliary obstruction due to pancreatic adenocarcinoma before endoscopic ultrasound does not influence the rate of tissue diagnosis if performed more than one day before EUS-FNA. Lack of immediate endoscopic ultrasound access should not preclude stent placement in appropriate patients with malignant biliary obstruction who will undergo EUS-FNA. ${ }^{54}$

\section{Ampullary adenocarcinoma}

Ampullary tumors account for approximately $5 \%$ of all gastrointestinal neoplasms affecting $0.04-0.64 \%$ of the general population in autopsy series. ${ }^{55-57}$ The most commonly affected patients are those with familial adenomatous polyposis with a $50-100 \%$ lifetime incidence of peri-ampullary adenomas. ${ }^{58-60}$ The associated morbidity and mortality of surgical resection for ampullary adenomas has led clinicians to seek less invasive techniques with endoscopic ampullectomy being first described in the 1980s. ${ }^{61}$ The first prospective RCT of the use of prophylactic pancreatic duct stenting for endoscopic ampullectomy published in 2005 was prematurely terminated because of an elevated incidence of pancreatitis in the group without pancreatic stenting (33\% vs 0\%) and suggested that pancreatic stent placement confers a protective effect ${ }^{62}$

Endoscopic ampullectomy guidelines have not been established. A literature review by Han et al. reveals diverse endoscopic practices regarding the use of biliary/pancreatic sphincterotomy, use and timing of pancreatic stenting, thermal ablation therapy and follow-up in ampullectomy. ${ }^{63}$ Though pancreatic duct stenting after endoscopic papillectomy of ampullary neoplasms is expected to contribute to the prevention of post-papillectomy pancreatitis, there is no consensus regarding the mode of resection, current or need for addition of biliary/pancreatic sphincterotomy and biliary stenting. ${ }^{64}$ Also, in a pilot study on 11 patients with ampullary neoplasm, pre-resection stenting with a polytetrafluoroethylene-insulated stent was shown to be feasible in the prevention of post-papillectomy pancreatitis. ${ }^{65}$ Prophylactic stenting of both the pancreatic and the biliary systems may further reduce post-endoscopic ampullectomy complications. ${ }^{66}$

\section{Benign biliary strictures}

Endoscopic treatment is the mainstay of therapy for benign billiary strictures and surgery is reserved for selected patients in whom endoscopic treatment fails or is not feasible. The endoscopic approach depends on stricture etiology and location, and generally involves the placement of one or multiple plastic stents, dilation of the stricture or a combination of these approaches. ${ }^{67}$ In benign strictures, endoscopic dilatation with short-term stenting seems to be effective and safe, and does not increase the risks of malignant transformation or complications after liver transplantation. Surgical bile duct resection and/or bilioenteric bypass are indicated only in patients with preserved liver function. ${ }^{68}$

Benign biliary strictures respond to placement of multiple large-bore plastic stents, although they require multiple procedures to exchange stents to prevent and/or treat stent occlusion. CSEMS, intended for palliation of malignant biliary obstruction, have been used to treat benign biliary diseases. Advantages include small pre-deployment and large postexpansion diameters. Lack of imbedding of the metal into the bile duct wall facilitates removal. For strictures, one CSEMS is inserted without the need for dilation and remains in place for up to six months. Successful removal has been reported in all cases. Long-term stricture resolution is achieved in up to $92 \%$. Adverse events include migration and new stricture formation. For treatment of complex bile leaks, the covering and large diameter allow successful closure in nearly all cases. Other uses of CSEMS include treatment of postsphincterotomy bleeding and closure of perforations. ${ }^{69}$

Multiple plastic biliary stents for benign non-hilar strictures were associated with a low rate of premature symptomatic stent occlusion at more than six months and a longer occlusion-free survival, thus suggesting that stents in benign strictures last longer and require less frequent replacement. ${ }^{70}$

\section{Primary sclerosing cholangitis}

Most patients with primary sclerosing cholangitis (PSC) develop fibrotic stenoses of the larger bile ducts. In patients with total or subtotal strictures of the large bile ducts, these so-called dominant stenoses may be treated by endoscopic balloon dilatation and/or stent placement, though in the large majority of cases a stent placement is not necessary. In fact, in a study by Gotthardt et al. on 171 PSC patients, 97 patients developed dominant strictures which were managed with 500 balloon dilatations and 5 stents. ${ }^{73}$ In a study by Kaya et al. on 71 PSC patients, 34 patients were treated with endoscopic balloon dilation alone, and 37 patients were treated with balloon dilation 
plus stent placement. There was no additional obvious benefit from stenting after balloon dilation in the treatment of dominant strictures in PSC patients. Stenting was also associated with more complications. ${ }^{74}$ Stenting may, however, still be necessary in those strictures which are resistant to dilatation, or where frequent repeat dilatation is necessary.

\section{Sphincter of Oddi dysfunction}

Pancreatic duct stenting gives significant protection against post-ERCP pancreatitis in patients with pancreatic sphincter hypertension undergoing biliary sphincterotomy. Stenting of the pancreatic duct should be strongly considered after biliary sphincterotomy for sphincter of Oddi dysfunction (SOD); pancreatic sphincter of Oddi manometry identifies which high-risk patients may benefit from pancreatic stenting. ${ }^{75}$ However, patients with suspected SOD who are found to have normal manometry results are also at high risk for post-ERCP pancreatitis. In a study by Saad et al. ${ }^{76}$ of 403 patients with suspected SOD but normal manometry, pancreatitis rates were $2.4 \%$ in the group undergoing prophylactic pancreatic duct stenting and $9.0 \%$ in the group who were not stented. The authors, therefore, concluded that temporary pancreatic duct stent placement reduces pancreatitis rates in patients with suspected SOD but normal manometry and an intact papilla. Their routine use is recommended when evaluating this difficult, high-risk patient population.

\section{Large or multiple common bile duct stones}

Difficult cases of bile duct stones are frequently treated successfully with lithotripsy. A stent should be applied when the common bile duct cannot be cleared completely. ${ }^{77}$ Little information is available on the outcomes of endoscopic sphincterotomy plus biliary stent placement without stone extraction as primary therapy at ERCP in the treatment of large or multiple common bile duct stones. Hong et al. retrospectively analyzed 52 patients with large (>20 mm) or multiple (3 or more) stones. ${ }^{78}$ The patients underwent endoscopic sphincterotomy and placement of plastic stents in the bile duct without stone extraction at the initial ERCP. Three or more months later, a second ERCP was carried out and stone removal was attempted. Differences in stone size and the largest CBD diameter before and after stenting were compared. Stone clearance and complications were also evaluated. After a median of 124 days of biliary plastic stent placement, the mean maximal stone diameter decreased from $16.6 \mathrm{~mm}$ to $10.0 \mathrm{~mm}(\mathrm{P}<0.01)$. The mean CBD diameter also decreased from $15.3 \mathrm{~mm}$ to 11.5 $\mathrm{mm}(\mathrm{P}<0.01)$. The total stone clearance at second ERCP was $94.2 \%$, only $5.7 \%$ of which need- ed mechanical lithotripsy. Biliary plastic stents plus endoscopic sphincterotomy without stone extraction as primary therapy at initial ERCP appears to be a safe and effective method in the management of large or multiple CBD stones. These findings were further replicated in 2 other studies by Fan et al. ${ }^{79}$ and Horiuchi et al. ${ }^{80}$

Itoi et al.$^{81}$ have described a new device for the removal of large bile duct stones. This is a combination of a large-diameter dilating balloon and sphincterotome. In a study on 18 patients, sphincterotomy was performed using this device, the catheter was then advanced into the bile duct and balloon dilation was performed by gradual inflation with diluted contrast medium under endoscopic and fluoroscopic guidance until it reached a diameter which allowed the stone to be removed. Technical success of large-diameter balloon dilatation after sphincterotomy was achieved in all cases with bile duct clearance performed in all but one case in the first session and bile duct clearance achieved in all cases on repeat endoscopy. No major complications were described. ${ }^{81}$

\section{Chronic pancreatitis}

The preferred therapeutic option in the management of chronic pancreatitis caused by stones is extracorporeal shock wave lithotripsy.An alternative involves the use of stents placed in the pancreatic duct endoscopically. Reports indicate that $30-76 \%$ of patients receiving such stents have symptomatic improvement over a period of 14-36 months of observation. ${ }^{82}$ Although these results seem encouraging, most of the data reported so far have been from relatively short-term, non-randomized studies. The issue is further complicated by the fact that pancreatic duct stents may not be entirely harmless; they may cause further pancreatic duct changes and potentiate chronic pancreatitis. ${ }^{83}$ Endoprosthesis occlusion and migration also seem to be relatively common.

Endoscopic stent drainage of both the pancreatic and the biliary duct for chronic pancreatitis with distal biliary benign strictures is an effective and minimally invasive therapeutic method. In a study by Zheng et al., ${ }^{84} 22$ patients diagnosed with chronic pancreatitis with distal benign biliary stricture underwent endoscopic treatment with ERCP, endoscopic sphincterotomy, endoscopic retrograde biliary drainage (ERBD) and endoscopic retrograde pancreatic drainage (ERPD) with stents. Sixtyeight ERCPs were successfully performed in 21 patients with 47 pancreatic duct stents and 39 biliary duct stents inserted. The rate of complications was $13.2 \%$ (9/68). The abdominal pain score after endoscopic treatment was significantly reduced. The levels of bilirubin and ala- nine transaminase in all 21 patients were also improved compared to those before endoscopic treatment.

\section{Pancreatic duct strictures}

Benign strictures of the main pancreatic duct are generally due to inflammation or fibrosis around the main pancreatic duct. Because ductal obstruction may lead to pain or acute pancreatitis superimposed on chronic pancreatitis, endoscopic therapy with balloon dilation or pancreatic duct stents for the treatment of dominant pancreatic duct strictures has been evaluated. Stricture dilation may be required to facilitate stent placement or stone removal. ${ }^{82}$ Data regarding the role of endoscopic therapy in treating main pancreatic duct strictures are inconsistent. Some, but not all, authors have reported high success rates (75-94\%) in treating pain by stenting of pancreatic duct strictures. ${ }^{85-87}$

In addition, although some authors have correlated clinical improvement to a decrease in the diameter of the main pancreatic duct upstream, others have not. Pancreatic stents are prone to occlusion and patients undergoing endoscopic therapy for pancreatic duct strictures may require frequent stent exchanges. Symptomatic improvement may persist after pancreatic stent removal despite persistence of the stricture. Confounding factors in the literature on pancreatic stent therapy are other therapies performed at the time of stent placement (e.g. pancreatic sphincterotomy, pancreatic stone removal) and the tendency of the chronic pancreatitis pain to come and go and decrease with time as pancreas function deteriorates. The optimum duration of stent placement, stent number and diameter and degree of balloon dilation are not known. Complications related to endoscopic therapy of pancreatic duct strictures include pain, pancreatitis, stent occlusion, proximal or distal stent migration, duodenal erosions, pancreatic infection, ductal perforation, and bleeding from pancreatic sphincterotomy.

The role of placing multiple stents in the pancreatic duct has been assessed by Costamagna et al. ${ }^{87}$ Nineteen patients with severe chronic pancreatitis and with a single pancreatic stent through a refractory dominant stricture in the pancreatic head underwent removal of this stent followed by balloon dilation of the stricture and insertion of the maximum number of stents allowed by the tightness of the stricture and the caliber of the pancreatic duct diameter. Stents were removed after 6-12 months. A median of 3 stents were placed through the major or minor papilla; stent diameter ranged from 8.5 to $11.5 \mathrm{Fr}$ and length from 4 to $7 \mathrm{~cm}$. During a mean follow up of 38 months after stent removal, $84 \%$ of patients were asymptomatic and $11 \%$ had symptomatic stricture recurrence. No major 
complications were recorded. This study showed that endoscopic multiple stenting of a dominant pancreatic duct stricture is feasible and safe.

\section{Pancreatic duct leaks}

Pancreatic duct disruptions or leaks can occur as a result of severe acute pancreatitis or chronic pancreatitis. Pancreatic duct leaks can often be treated with endoscopic placement of transpapillary stents in a manner similar to the use of biliary stents for closing bile duct leaks. ${ }^{88}$ Endoscopic therapy is successful in closing the leaks in approximately $60 \%$ of patients. Factors associated with a better outcome in duct disruption include a partial disruption, successfully bridging the disruption with a stent, and longer duration of stent placement (approximately 6 weeks). Major pancreatic disruption secondary to pancreatic trauma can also be managed by pancreatic duct stenting. ${ }^{89}$

\section{Post-endoscopic retrograde cholangiopancrea pancreatitis pro- phylaxis}

Pancreatitis is the most common and potentially serious complication following ERCP. Post-ERCP pancreatitis (PEP) is caused mostly by postprocedural papillary edema and retention of pancreatic juice. The European Society of Gastrointestinal Endoscopy guidelines on the prophylaxis of post-ERCP pancreatitis ${ }^{90}$ recommend that prophylactic pancreatic stent placement helps prevent post-ERCP pancreatitis in patients who are at high risk. Short 5-Fr diameter plastic pancreatic stents are currently recommended. Passage of the stent from the pancreatic duct should be evaluated within 5 10 days of placement and retained stents should be promptly removed endoscopically.

In a randomized controlled trial on 426 patients at 37 endoscopic units, Sofuni et al. ${ }^{91}$ showed that placement of a pancreatic duct stent reduces the incidence of PEP and that several risk factors are associated with PEP. Patients were assigned randomly to groups that received ( $\mathrm{S}$ group, $\mathrm{n}=213$ ) or did not ( $\mathrm{nS}$ group, $n=213$ ) receive stents. The stent used was temporary, $5 \mathrm{~F}$ in diameter, $3 \mathrm{~cm}$ long, and straight with an unflanged inner end. The frequencies of PEP in the $\mathrm{S}$ and $\mathrm{nS}$ groups were 7.9 and $15.2 \%$, respectively; the lower incidence of PEP in the $\mathrm{S}$ group was statistically significant based on the full analysis set $(\mathrm{P}=0.021)$. There were significant differences in PEP incidence between groups in multivariate analysis for the following risk factors: pancreatography first, non-placement of a pancreatic duct stent after ERCP, procedure time of 30 min or more, sampling of pancreatic tissue by any method, intraductal ultrasonography, and difficulty of cannulation ( $\geq 15 \mathrm{~min}$ ). Patients with more than 3 risk factors had a significantly greater incidence of pancreatitis.

A meta-analysis of eight randomized controlled trials $^{92}$ (656 subjects) showed that prophylactic pancreatic stents decreased the odds of post-ERCP pancreatitis (odds ratio $0.22 ; 95 \%$ CI $0.12-0.38 ; \mathrm{P}<0.01$ ) with 8 needed in order to treat. Stents also decreased the level of hyperamylasaemia. The size of the ideal pancreatic stent to prevent post-ERCP pancreatitis has yet to be determined. Pahk et al..$^{93}$ reviewed the outcomes of 346 prophylactic pancreatic stents in 308 patients and showed that prophylactic stents significantly reduced the risk of postERCP pancreatitis and nearly eliminated severe pancreatitis. There was no significant difference between the $4 \mathrm{Fr}$ and 5 Fr stents in the reduction of post-ERCP pancreatitis but spontaneous migration was more frequent with the 4-Fr stent. Zolotarevsky et al. ${ }^{94}$ have, however, shown that placement of $5 \mathrm{Fr}$ pancreatic stents is easier, faster and requires fewer wires than the $3 \mathrm{Fr}$ stent.

Removal of retained prophylactic pancreatic stents may cause mild or moderate acute pancreatitis. In a study by Moffatt $e$ t al.,95 acute pancreatitis occurred after prophylactic pancreatic stent removal in 7 of 230 (3.0\%) cases of retained stents. This risk of acute pancreatitis may diminish the overall efficacy of prophylactic stents use by delaying the occurrence of post-ERCP pancreatitis rather than eliminating it. This implies that prophylacyic pancreatic stents should be used only in patients at high risk for post-ERCP pancreatitis. Among the complications of pancreatic stenting, proximal (upstream) migration of pancreatic stents occurs with a reported incidence of $5.2 \%$ and may induce morphological changes in the pancreatic duct and pancreatitis if left without retrieval. ${ }^{96-101}$ Similar to extraction of migrated biliary stents, more than $80 \%$ of proximally migrated pancreatic stents can be retrieved endoscopically by indirect traction with stone extraction balloon or direct traction with foreign body grasp forceps, snares or basket. ${ }^{102-106}$ In difficult cases, several retrieval techniques have been successfully applied and introduced in case reports, including the wire-guided snare lasso technique, ${ }^{107}$ using a Soehendra stent retriever, SpyGlass assisted stent retrieval, ${ }^{108}$ and interventional cardiology accessories. ${ }^{109}$

Gong et al. ${ }^{110}$ have described an algorithm that has allowed them to retrieve all of 15 pancreatic stents ( $5 \mathrm{Fr} n=6 ; 7 \mathrm{Fr} n=9$ ) that had migrated proximally. The stent retrieval was performed by an experienced endoscopist. The existing strictures in the proximal pancreatic duct were dilated with dilation balloon or bougie before stent retrieval. Endoscopic sphincterotomy or dilation was performed on the intact minor papilla if retrieval of the prox- imally migrated pancreatic stents (PMPS) from the dorsal pancreatic duct was necessary. All of the PMPSs were retrieved initially with balloon extraction by inflating an over-the-wire stone extraction balloon alongside or above the migrated stent and dragging the stent distally. If balloon extraction failed after five attempts, another accessory was used. In patients without pancreatic duct dilation, a rat-tooth forceps was introduced into the pancreatic duct by grasping the guide wire to the distal end or the shaft of the stent. Direct grasping of the stent was then conducted under fluoroscopy. If this approach failed after five attempts, a rescue approach was attempted. In patients with pancreatic duct dilation, retrieval with a rat-tooth forceps was also tried first. If it failed after five attempts, a wire-guided basket was used to grasp the stent and a rescue approach was considered after five failed attempts.

Recently, wire-guided selective cannulation of the bile duct has been proposed as a technique with a high rate of success and less risk of post-ERCP pancreatitis. Nambu et al. ${ }^{111}$ compared the post-ERCP pancreatitis rates using the wire-guided cannulation method ( 86 cases) with the standard cannulation method (86 cases). The standard method had a postERCP pancreatitis rate of $6 \%$ while only $2.3 \%$ of the wire-guided method had post-ERCP pancreatitis. In addition, all cases of pancreatitis in the wire-guided cannulation group were mild, with a comparable success rate of cannulation between both groups. ${ }^{111}$

\section{Post-cholecystectomy biliary injuries}

Bile leak from tears in the biliary system following cholecystectomy is a complication which can be managed by stent insertion during ERCP. ${ }^{112,113}$ Endoscopic stenting helps to avoid surgery in more than $80 \%$ of patients bearing postcholecystectomy common bile duct strictures. However, in a long-term follow up after biliary stent placement for postcholecys tectomy biliary strictures, Tuvignon et al. ${ }^{114}$ showed that a persistent anomaly on cholangiography at the time of stent removal is a strong predictor of recurrence and may lead to surgery being considered. Biliary stenting seems to be a more effective method than endoscopic sphincterotomy in the management of postcholecystectomy bile leakage and without CBD dilatation. ${ }^{115}$

\section{Biliary strictures after liver trans- plantation}

Biliary strictures are one of the most common complications following liver transplantation, representing an important cause of morbidity and mortality in transplant recipients. The reported incidence of biliary stricture is 5$15 \%$ following deceased donor liver transplan- 
tations (DDLT) and 28-32\% following living donor liver transplantations (LDLT). ${ }^{116}$ Bile duct strictures following liver transplantation are classified as anastomotic (AS) or nonanastomotic strictures (NAS). NAS are characterized by a far less favorable response to endoscopic management, higher recurrence rates, graft loss and the need for retransplantation. Current endoscopic strategies to correct biliary strictures following liver transplantation include repeated balloon dilatations and the placement of multiple side-by-side plastic stents. Endoscopic balloon dilatation with stent placement is successful in the majority of AS patients. In patients for whom gaining biliary access is technically difficult, a combined endoscopic and percutaneous/surgical approach proves quite useful.

Management of patients with NAS is difficult since the accumulation of biliary sludge and casts makes therapy particularly difficult because of rapid stent occlusion. Treatment of NAS did not result in significant long-term improvement of liver chemistries. The poor response of non-anastomotic stenoses to treatment does not seem to vary with etiology. ${ }^{117}$ Most importantly, NAS resulted in significantly increased graft loss.

NAS in LDLT are more resistant to endoscopic treatment with average success rate of $25-33 \%$, which is far below the $60 \%$ success rate seen with NAS in DDLT. ${ }^{118,119}$ Endoscopic therapy of non-anastomotic strictures typically consists of extraction of the biliary sludge and casts and balloon dilation of all accessible strictures followed by placement of plastic stents with 3 -monthly replacement.117 However, balloon dilation of all strictures is not feasible and rapid stent clogging frequently occurred when managing NAS. Therefore, patients with NAS may require early retransplantation and endoscopic therapy appears to play a more prominent role as a bridge to liver retransplantation. ${ }^{119}$

In anastomotic strictures, the conventional method of endoscopic treatment consists of identification of the opening of the stricture followed by cannulation by the guidewire, balloon dilatation of the stricture, and subsequent placement of plastic stents. Balloon dilation alone without stent placement is only successful in approximately $40 \%$ of cases. ${ }^{120}$ However, balloon dilation with additional stent placement appears to be more successful with a durable outcome in $75 \%$ of patients with anastomotic strictures. The stents are generally replaced by larger stents every three months to prevent the complication of clogging, cholangitis, or stone formation. ${ }^{121}$ Dual or multiple stents provide greater dilatation and have, therefore, shown better results than single stents. ${ }^{119}$ Placement of not one, but multiple side-by-side plastic stents, further increases successful outcomes in $80-90 \%$ of patients. ${ }^{122,123}$

In some patients, a transient narrowing at a duct to duct connection appear within the first 30 to 60 days after transplantation, due to postoperative edema and inflammation. This type of stricture responds well to balloon dilatation and temporary stent placement. ${ }^{124}$ Most patients with anastomotic strictures require repeat ERCP sessions every three months with balloon dilation of $6-10 \mathrm{~mm}$ and multiple stents of 7-10 Fr repeated for 12-24 months. ${ }^{124,125}$ An increasing number of stents can be used at each session to achieve a maximum diameter. The treatment is usually completed in one year with an average of 3-4 stent exchange sessions. The overall long-term success rate of endoscopic treatment for AS associated with DDLT is in the range of 70-100\%. ${ }^{126-128}$

However, endoscopic treatment success rates in AS after LDLT appear significantly lower than AS for DDLT at $37-71 \%{ }^{129,130}$ When AS are treated appropriately, the long-term results in terms of patient and graft survival are the same as those for matched controls without AS. ${ }^{131}$ A protocol of accelerated dilation every two weeks, and a shortened stenting period of an average of 3.6 months, showed some encouraging results with a high $87 \%$ success rate. ${ }^{123}$ In patients with duct to duct anastomosis, endoscopic management is, therefore, first line, and it appears that while repeat endoscopic treatment is needed, shorter intervals between treatments may ultimately reduce the time needed for successful longterm outcomes. Despite limited data, there is some experience in temporary placement of CSEMS to reduce the need for repeated stent exchanges but long-term results are not yet available.

\section{Conclusions}

ERCP stents are one of the most important tools in the endoscopic management of hepatobiliary and pancreatic diseases. Plastic and metal stents have specific indications. The covered self-expandable metal stents have been shown to be safe to use in a number of conditions, particularly those which require prolonged ( $>3$ months) stenting.

\section{References}

1. Nguyen K, Sing JT Jr. Review of endoscopic techniques in the diagnosis and management of cholangiocarcinoma. World $\mathrm{J}$ Gastroenterol 2008;14:2995-9.

2. Kasher JA, Corasanti JG, Tarnasky PR, et al. A multicenter analysis of safety and outcome of removal of a fully covered selfexpandable metal stent during ERCP. Gastrointest Endosc 2011;73:1292-7.

3. Fogel EL, de Bellis M, McHenry L, et al. Effectiveness of a new long cytology brush in the evaluation of malignant biliary obstruction: a prospective study. Gastrointest Endosc 2006;63:71-7.

4. de Bellis M, Sherman S, Fogel EL, et al. Tissue sampling at ERCP in suspected malignant biliary strictures (Part 2). Gastrointest Endosc 2002;56:720-30.

5. Roayaie S, Guarrera JV, Ye MQ, et al. Aggressive surgical treatment of intrahepatic cholangiocarcinoma: predictors of outcomes. J Am Coll Surg 1998;187:365-72.

6. Weber SM, Jarnagin WR, Klimstra D, et al. Intrahepatic cholangiocarcinoma: resectability, recurrence pattern, and outcomes. J Am Coll Surg 2001;193:384-91.

7. Khan SA, Davidson BR, Goldin R, et al. Guidelines for the diagnosis and treatment of cholangiocarcinoma: consensus document. Gut 2002;51:vi1-vi9.

8. De Palma GD, Galloro G, Siciliano S, et al. Unilateral versus bilateral endoscopic hepatic duct drainage in patients with malignant hilar biliary obstruction: results of a prospective, randomized, and controlled study. Gastrointest Endosc 2001;53:547-53.

9. Soderlund C, Linder S. Covered metal versus plastic stents for malignant common bile duct stenosis: a prospective, randomized, controlled trial. Gastrointest Endosc 2006;63:986-95.

10. Kassis M, Boyer J, Dumas R, et al. Plastic or metal stents for malignant stricture of the common bile duct? Results of a randomized prospective study. Gastrointest Endosc 2003;57:178-82.

11. Prat F, Chapat O, Ducot B, et al. A randomized trial of endoscopic drainage methods for inoperable malignant strictures of the common bile duct. Gastrointest Endosc 1998;47:1-7.

12. Katsinelos P, Beltsis A, Chatzimavroudis G, et al. Endoscopic management of occluded biliary uncovered metal stent: A multicenter experience. World J Gastroenterol 2011;17:98-104.

13. Yoon WJ, Ryu JK, Lee JW, et al. Endoscopic management of occluded metal biliary stents: Metal versus 10F plastic stents. World J Gastroenterol 2010;16:5347-52.

14. Bakhru M, Ho HC, Gohil J, et al. Fully-covered, self-expandable metal stents (CSEMS) in malignant distal biliary strictures: mid-term evaluation. J Gastroenterol Hepatol 2011;26:1022-7.

15. Strasberg SM. ERCP and surgical intervention in pancreatic and biliary malignancies. Gastrointest Endosc 2002;56:S213- 
S217.

16. Freeman ML, Sielaff TD. A modern approach to malignant hilar biliary obstruction. Rev Gastroenterol Disord 2003;3:187-201.

17. Kanai M, Nimura Y, Kamiya J, et al. Preoperative intrahepatic segmental cholangitis in patients with advanced carcinoma involving the hepatic hilus. Surgery 1996;119:498-504.

18. Kennedy TJ, Yopp A, Qin Y, et al. Role of preoperative biliary drainage of liver remnant prior to extended resection for hilar cholangiocarcinoma. HPB 2009;11:445-51.

19. Gouma DJ, Coelho JC, Fisher JD, et al. Endotoxemia after relief of biliary obstruction by internal and external drainage in rats. Am J Surg 1986;151:476-9.

20. Arai T, Yoshikai Y, Kamiya J, et al. Bilirubin impairs bactericidal activity of neutrophils through an antioxidant mechanism in vitro. J Surg Res 2001;96:107-13.

21. Abe T, Arai T, Ogawa A, et al. Kupffer cellderived interleukin 10 is responsible for impaired bacterial clearance in bile ductligated mice. Hepatology 2004;40:414-23.

22. Tsuzuki T, Ogata Y, Iida S, et al. Carcinoma of the bifurcation of the hepatic ducts. Arch Surg 1983;118:1147-51.

23. Nimura Y, Hayakawa N, Kamiya J, et al. Hepatic segmentectomy with caudate lobe resection for bile duct carcinoma of the hepatic hilus. World J Surg 1990;14:53544.

24. Nagino M, Hayakawa N, Nimura $\mathrm{Y}$, et al. Percutaneous transhepatic biliary drainage in patients with malignant biliary obstruction of the hepatic confluence. Hepatogastroenterology 1992;39:296-300.

25. Nimura Y, Kamiya J, Kondo S, et al. Aggressive preoperative management and extended surgery for hilar cholangiocarcinoma: Nagoya experience. J Hepatobil Pancreat Surg 2000;7:155-62.

26. Suzuki H, Iyomasa S, Nimura Y, et al. Internal biliary drainage, unlike external drainage, does not suppress the regeneration of cholestatic rat liver after partial hepatectomy. Hepatology 1994;20:1318-22.

27. Saiki S, Chijiiwa K, Komura M, et al. Preoperative internal biliary drainage is superior to external biliary drainage in liver regeneration and function after hepatectomy in obstructive jaundiced rats. Ann Surg 1999;230:655-62.

28. Kawakami H, Kondo S, Kuwatani M, et al. Preoperative biliary drainage for hilar cholangiocarcinoma: which stent should be selected? J Hepatobiliary Pancreat Sci 2011;18:630-5.

29. Nimura Y. Preoperative biliary drainage before resection of cholangiocarcinoma. HPB 2008;10:130-3.

30. Hatfield ARW, Tobias R, Terblanche J, et al.
Preoperative external biliary drainage in obstructive jaundice. A prospective controlled clinical trial. Lancet 1982;2:896-9.

31. McPherson GA, Benjamin IS, Hodgson HJ, et al. Pre-operative percutaneous transhepatic biliary drainage: the results of a controlled trial. Br J Surg 1984;71:371-5.

32. Pitt HA, Gomes AS, Lois JF, et al. Does preoperative percutaneous biliary drainage reduce operative risk or increase hospital cost? Ann Surg 1985;201:545-53.

33. Lai ECS, Mok FPT, Fan ST, et al. Preoperative endoscopic drainage for malignant obstructive jaundice. Br J Surg 1994;81:1195-8.

34. Telford JJ, Carr-Locke DL, Baron TH, et al. A randomized trial comparing uncovered and partially covered self-expandable metal stents in the palliation of distal malignant biliary obstruction. Gastrointest Endosc 2010;72:907-14.

35. Kullman E, Frozanpor F, Soderlund C, et al. Covered versus uncovered self-expnadable nitinol stents in the palliative treatment of malignant distal biliary obstruction: results from a randomized, multicenter study. Gastrointest Endosc 2010;72:915-23.

36. Fumex F, Coumaros D, Napoleon B, et al. Similar performance but higher cholecystitis rate with covered biliary stents: results from a prospective multicenter evaluation. Endoscopy 2006;38:787-92.

37. Park do H, Kim MH, Choi JS, et al. Covered versus uncovered wallstent for malignant extrahepatic biliary obstruction: a cohort comparative analysis. Clin Gastroenterol Hepatol 2006;4:790-6.

38. Aljiffry M, Walsh MJ, Molinari M. Advances in diagnosis, treatment and palliation of cholangiocarcinoma: 1990-2009. World J Gastroenterol. 2009;15:4240-62.

39. Hamada T, Nakai Y, Matsubara S, et al. Anchor-wire technique for multiple plastic biliary stents to prevent stent dislocation. World J Gastroenterol 2011;17:3366-8.

40. Allison MC, Sandoe JAT, Tighe R, et al. Antibiotic prophylaxis in gastrointestinal endoscopy. Gut 2009;58:869-80.

41. Decker C, Christein JD, Phadnis MA, et al. Biliary metal stents are superior to plastic stents for preoperative biliary decompression in pancreatic cancer. Surg Endosc 2011;25:2364-7.

42. Boulay BR, Gardner TB, Gordon SR. Occlusion rate and complications of plastic biliary stent placement in patients undergoing neoadjuvant chemoradiotherapy for pancreatic cancer with malignant biliary obstruction. J Clin Gastroenterol 2010;44: 452-5.

43. Katsinelos P, Kountouras J, Germanidis G, et al. Sequential or simultaneous placement of self-expandable metallic stents for palliation of malignant biliary and duode- nal obstruction due to unresectable pancreatic head carcinoma. Surg Laparosc Endosc Percutan Tech 2010;20:410-5.

44. Singal AK, Ross WA, Guturu P, et al. SelfExpanding Metal Stents for Biliary Drainage in Patients with Resectable Pancreatic Cancer: Single-Center Experience with 79 Cases. Dig Dis Sci 2011;56:3678-84.

45. Weber A, Kehl V, Mittermeyer T, et al. Prognostic factors for survival in patients with unresectable pancreatic cancer. Pancreas 2010;39:1247-53.

46. Weston BR, Ross WA, Liu J, et al. Clincal outcomes of nitinol and stainless steel uncovered metal stents for malignant biliary strictures: is there a difference? Gastrintest Endosc 2010;72:1195-200.

47. Buxbaum JL, Biggins SW, Bagatelos KC, et al. Inoperable pancreatic cancer patients who have prolonged survival exhibit an increased risk of cholangitis. JOP 2011;12:377-83.

48. Cote GA, Kumar N, Ansstas M, et al. Risk of post-ERCP pancreatitis with placement of self-expandable metallic stents. Gastrintest Endosc 2010;72:748-54.

49. Hamada T, Isayama $H$, Nakai $Y$, et al. Duodenal invasion is a risk factor for the early dysfunction of biliary metal stents in unresectable pancreatic cancer. Gastrointest Endosc 2011;74:548-55.

50. Eshuis WJ, van der Gaag NA, Auws EA, et al. Therapeutic delay and survival after surgery for cancer of the pancreatic head with or without preoperative biliary drainage. Ann Surg 2010;252:840-9.

51. Bonin EA, Baron TH. Preoperative biliary stents in pancreatic cancer. J Hepatobiliary Pancreat Sci 2011;18:621-9.

52. Lytras D, Olde Damink SW, Amin Z, et al. Radical surgery in the presence of biliary metallic stents: revising the palliative scenario. J Gastrointest Surg 2011;15:489-95.

53. Siddiqui AA, Mehendiratta V, Loren et al. Fully Covered Self-expandable Metal stents are Effective and Safe to Treat Distal Malignant Biliary Strictures, Irrespective of surgical Resectabiility Status. J Clin Gastroenterol 2011;45:824-7.

54. Fisher JM, Gordon SR, Gardner TB. The impact of prior biliary stenting on the accuracy and complication rate of endoscopic ultrasound fine-needle aspiration for diagnosing pancreatic adenocarcinoma. Pancreas 2011;40:21-4.

55. Scarpa A, Capelli P, Zamboni G, et al. Neoplasia of the ampulla of Vater. Ki-ras and p53 mutations. Am J Pathol 1993;142:1163-72.

56. Shapiro PF, Lifvendahl RA. Tumors of the Extrahepatic Bile-ducts. Ann Surg 1931;94:61-79.

57. Rosenberg J, Welch JP, Pyrtek LJ, et al. 
Benign villous adenomas of the ampulla of Vater. Cancer 1986;58:1563-8.

58. Yao T, Ida M, Ohsato K, et al. Duodenal lesions in familial polyposis of the colon. Gastroenterology 1977;73:1086-92.

59. Burke CA, Beck GJ, Church JM, et al. The natural history of untreated duodenal and ampullary adenomas in patients with familial adenomatous polyposis followed in an endoscopic surveillance program. Gastrointest Endosc 1999;49:358-64.

60. Shemesh E, Bat L, A prospective evaluation of the upper gastrointestinal tract and periampullary region in patients with Gardner syndrome. Am J Gastroenterol 1985;80:825-7

61. Ponchon T, Berger F, Chavaillon A, et al. Contribution of endoscopy to diagnosis and treatment of tumors of the ampulla of Vater. Cancer 1989;64:161-7

62. Harewood GC, Pochron NL, Gostout CJ. Prospective, randomized, controlled trial of prophylactic pancreatic stent placement for endoscopic snare excision of the duodenal ampulla. Gastrointest Endosc 2005;62:367-70.

63. Han J, Kim MH. Endoscopic papillectomy for adenomas of the major duodenal papilla (with video). Gastrointest Endosc 2006;63:292-301.

64. Ito K, Fujita N, Noda Y. Endoscopic diagnosis and treatment of ampullary neoplasm. Dig Endosc 2011;23:113-7.

65. Hwang JC, Kim JH, Lim SG, et al. Endoscopic resection of ampullary adenoma after a new insulated plastic pancreatic stent placement: a pilot study. J Gastroenterol Hepatol 2010;25:1381-5.

66. Yamao T, Isomoto $\mathrm{H}$, Kohno $\mathrm{S}$, et al. Endoscopic snare papillectomy with biliary and pancreatic stent placements for tumors of the major duodenal papilla. Surg Endosc 2010;24:119-24.

67. Zepeda-Gomez S, Baron TH. Benign biliary strictures: current endoscopic management. Nat Rev Gastroenterol Hepatol 2011;8:573-81.

68. Aljiffry M, Renfrew PD, Walsh MJ, et al. Analytical review of diagnosis and treatment strategies for dominant bile duct strictures in patients with primary sclerosing cholangitis. HPB 2011;13:79-90.

69. Baron TH. Covered self-expandable metal stents for benign biliary tract diseases. Curr Opin Gastroenterol 2011;27:262-7.

70. Lawrence C, Romagnuolo J, Payne KM, et al. Low symptomatic premature stent occlusion of multiple plastic stents for benign biliary strictures: comparing standard and prolonged stent change intervals. Gastrointest Endosc 2010;72:558-63.

71. Gotthardt D, Stehl A. Endoscopic retrograde cholangiopancreatography in diagnosis and treatment of primary sclerosing cholangitis. Clin Liver Dis 2010;14:349-58.

72. Stiehl A. Primary sclerosing cholangitis: the role of endoscopic therapy. Semin Liver Dis 2006;26:62-8.

73. Gotthardt DN, Rudolph G, Kloters-Plachy P, et al. Endoscopic dilation of dominant stenoses in primary sclerosing cholangitis: outcome after long-term treatment. Gastrointest Endosc 2010;71:527-34.

74. Kaya M, Petersen BT, Angulo P, et al. Balloon dilation compared to stenting of dominant strictures in primary sclerosing cholangitis. Am J Gastroenterol 2001;96: 1059-66.

75. Tarnasky PR, Paalesch YY, Cunningham JT, et al. Pancreatic stenting prevents pancreatitis after biliary sphincterotomy in patients with sphincter of Oddi dysfunction. Gastroenterology 1998;115:1518-24.

76. Saad AM, Fogel EL, McHenry L, et al. Pancreatic duct stent placement prevents post-ERCP pancreatitis in patients with suspected sphincter of Oddi dysfunction but normal manometry results. Gastrointest Endosc 2008;67:255-61.

77. Akcakaya A, Ozkan OV, Bas G, et al. Mechanical lithotripsy and/or stenting in management of difficult common bile duct stones. Hepatobiliary Pancreat Dis Int 2009;8:524-8.

78. Hong WD, Zhu QH, Huang QK. Endoscpopic sphicterotomy plus endoprosthesis in the treatment of large or multiple common bile duct stones. Dig Endosc 2011;23:240-3.

79. Fan Z, Hawes R, Lawrence C, et al. Analysis of plastic stents in the treatment of large common bile duct stones in 45 patients. Dig Endosc 2011;23:86-90.

80. Horiuchi A, Nakayama Y, Kajiyama M, et al. Biliary stenting in the management of large or multiple common bile duct stones. Gastrointest Endosc 2010;71:1200-3.

81. Itoi T, Sofuni A, Itokawa F, et al. New largediameter balloon-equipped sphincterotome for removal of large bile duct stones. Gastrointest Endosc 2010;72:825-30.

82. Christodoulou DK, Tsianos EV. Role of endoscopic retrograde cholangiopancreatography in pancreatic diseases. World $\mathrm{J}$ Gastroenterol 2010;16:4755-61.

83. Nguyen-Tang T, Dumonceau JM. Endoscopic treatment in chronic pancreatitis, timing, duration and type of intervention. Best Pract Res Clin Gastroenterol 2010;24:281-98.

84. Zheng MW, Qin MF, Cai W. Endoscopic pancreatic duct and biliary duct stenting in treatment of chronic pancreatitis with distal benign biliary stricture: a single-center experience. Hepatobiliary Pancreat Dis Int 2011;10:539-43.

85. Catalano MF. Endoscopic treatment of pancreatic duct strictures. Tech Gastrointest
Endosc 1999;1:168-74.

86. Cremer M, Deviere J, Delhaye M, et al. Endoscopic management of chronic pancreatitis. Acta Gastroenterol Belg 1993;56:192-200.

87. Costamagna G, Bulajic M, Tringali A, et al. Multiple stenting of refractory pancreatic duct strictures in severe chronic pancreatitis: long-term results. Endoscopy 2006; 38:254-9.

88. Bracher GA, Manocha AP, DeBanto JR, et al. Endoscopic pancreatic duct stenting to treat pancreatic ascites. Gastrointest Endosc 1999;49:710-5.

89. Abe T, Nagai T, Murakami $K$, et al. Pancreatic injury successfully treated with endoscopic stenting for major pancreatic duct disruption. Intern Med 2009;48:188992.

90. Dumonceau JM, Andriulli A, Deviere J, et al. ESGE Guideline: Prophylaxis of postERCP pancreatitis. Endoscopy 2010;42:503-15.

91. Sofuni A, Maguchi H, Mukai T, et al. Endoscopic pancreatic uct stents reduce the incidence of post-endoscopic retrograde cholangiopancreatography pancreatitis in high risk patients. Clin Gatroenterol Hepatol 2011;9:851-8.

92. Choudhary A, Bechtold ML, Arif M, et al. Pancreatic stents for prophylaxis against post-ERCP pancreatitis: a meta-analysis and systematic review. Gastrointest Endosc 2011;73:275-82.

93. Pahk A, Rigaux J, Poreddv V, et al. Prophylactic Pancreatic Stents: Does Size Matter? A Comparison of 4-Fr and 5-Fr Stents in Reference to post-ERCP Pancreatitis and Migration Rate. Dig is Sci 2011;56:3058-64.

94. Zolotarevsky E, Fehmi SM, Anderson MA, et al. Prophylactic 5-Fr pancreatic duct stents are superior to 3-Fr stents; a randomized controlled trial. Endoscopy 2011;43:325-30.

95. Moffatt DC, Cote GA, Fogel EL, et al. Acute pancreatitis after removal of retained prophylactic pancreatic stents. Gastrointest Endosc 2011;73:980-6.

96. Sharara AI, Leung JW. Endoscopic extraction of proximally migrated biliary endoprostheses using a grasping rat-tooth forceps. Gastrointest Endosc 1995;41:619-20.

97. Chahal P, Baron TH, Petersen BT, et al. Pancreatic stent prophylaxis of post endoscopic retrograde cholangiopancreatography pancreatitis: spontaneous migration rates and clinical outcomes. Minerva Gastroenterol Dietol 2007;53:225-30.

98. Kakutani H, Imazu H, Uchiyama Y, et al. Unusual migration of pancreatic stent used for transpapillary drainage of pancreatic pseudocyst. Gastrointest Endosc 2006;64:275-6. 
99. Vinod J, Palance A, Haber G. An unusual complication of a gastrocystic stent in the management of pancreatic pseudocyst. Gastrointest Endosc 2008;67:1199-201.

100.Bakman YG, Safdar K, Freeman ML. Significant clinical implications of prophylactic pancreastic stent placement in previously normal pancreatic ducts. Endoscopy 2009;41:1095-8.

101.Attasaranya S, Fogel EL, Sherman S. A lowlying pancreatic stent and an obscure pancreatic stent. Gastrointest Endosc 2008;67:972-3.

102.Lawrence C, Cotton PB, Romagnuolo J, et al. Small prophylactic pancreatic duct stents: an assessment of spontaneous passage and stent-induced ductal abnormalities. Endoscopy 2007;39:1082-5.

103.Sakai Y, Tsuyuguchi T, Ishihara T, et al. Cholangiopancreatography troubleshooting: the usefulness of endoscopic retrieval of migrated biliary and pancreatic stents. Hepatobiliary Pancreat Dis Int 2009;8:6327.

104. Rerknimitr R, Phuangsombat W, Naprasert P. Endoscopic removal of proximally migrated pancreatic stent by a grasping tripod. Endoscopy 2007;39:E42.

105.Price LH, Brandabur JJ, Kozarek RA, et al. Good stents gone bad: endoscopic treatment of proximally migrated pancreatic duct stents. Gastrointest Endosc 2009;70:174-9.

106.Lahoti S, Catalano MF, Geenen JE, et al. Endoscopic retrieval of proximally migrated biliary and pancreatic stents: experience of a large referral center. Gastrointest Endosc 1998;47:486-91.

107.Vila JJ, Ruiz-Clavijo D, Fernández-Urién I, et al. Endoscopic retrieval of a proximally migrated pancreatic stent: variation of the lasso technique. Endoscopy 2010;42:E5-6

108.Kantsevoy SV, Frolova EA, Thuluvath PJ. Successful removal of the proximally migrated pancreatic winged stent by using the SpyGlass visualization system. Gastrointest Endosc 2010;72:454-5.

109.Baron TH, Dean LS, Morgan DE, et al. Proximal migration of a pancreatic duct stent: endoscopic retrieval using interventional cardiology accessories. Gastrointest Endosc 1999;50:124-5.

110.Gong B, Sun B, Hao LX, et al. Usefulness of an algorithm for endoscopic retrieval of proximally migrated 5Fr and 7Fr pancreatic stents. Hepatobiliary Pancreatic Dis Int 2011;10:196-200.

111.Nambu T, Ukita T, Shigoka H, et al. Wireguided selective cannulation of the bile duct with a sphincterotome: a prospective randomized comparative study with the standard method. Scand J Gastroenterol 2011;46;109-15.

112.Fathy 0, Wahab MA, Hamdy E, et al. Postcholecystectomy biliary injuries: one center experience. Hepatogastroenterology 2011;58:719-24.

113.Singh V, Singh G, Verma GR, et al. Endoscopic management of postcholecystectomy biliary leakage. Hepatobiliary Pancreat Dis Int 2010;9:409-13.

114.Tuvignon N, Liguory C, Ponchon T, et al. Long-term follow-up after biliary stent placement for postcholecystectomy bile duct strictures: a multicenter study. Endoscopy 2011;43:208-16.

115.Dolay K, Soylu A, Aygun E. The role of ERCP in the management of bile leakage: endoscopic sphincterotomy versus biliary stenting. J Laparoendosc Adv Surg Tech A 2010;20:455-9.

116.Choong HR, Sung KL. Biliary Strictures after Liver Transplantation. Gut Liver 2011;5:133-42.

117.Guichelaar MM, Benson JT, Malinchoc M, et al. Risk factors for and clinical course of non-anastomotic biliary strictures after liver transplantation. Am J Transplant 2003;3:885-90.

118.Tada S, Yazumi S, Chiba T. Endoscopic management is an accepted first-line therapy for biliary complications after adult living donor liver transplantation. Am J Gastroenterol 2007;102:1331.

119.Zajko AB, Campbell WL, Logsdon GA, et al. Cholangiographic findings in hepatic artery occlusion after liver transplantation. AJR Am J Roentgenol 1987;149:485-9.

120.Schwartz DA, Petersen BT, Poterucha JJ, et al. Endoscopic therapy of anastomotic bile duct strictures occurring after liver transplantation. Gastrointest Endosc 2000;51:169-74.

121.Rizk RS, McVicar JP, Emond MJ, et al. Endoscopic management of biliary strictures in liver transplant recipients: effect on patient and graft survival. Gastrointest Endosc 1998;47:128-35.
122.Costamagna G, Pandolfi M, Mutignani M, et al. Long-term results of endoscopic management of postoperative bile duct strictures with increasing numbers of stents. Gastrointest Endosc 2001;54:162-8.

123.Morelli G, Fazel A, Judah J, et al. Rapidsequence endoscopic management of posttransplant anastomotic biliary strictures. Gastrointest Endosc 2008;67:879-85.

124.Thuluvath PJ, Pfau PR, Kimmey MB, et al. Biliary complications after liver transplantation: the role of endoscopy. Endoscopy 2005;37:857-63.

125.Morelli J, Mulcahy HE, Willner IR, et al. Long-term outcomes for patients with post-liver transplant anastomotic biliary strictures treated by endoscopic stent placement. Gastrointest Endosc 2003;58: 374-9.

126.Rerknimitr R, Sherman S, Fogel EL, et al. Biliary tract complications after orthotopic liver transplantation with choledochocholedochostomy anastomosis: endoscopic findings and results of therapy. Gastrointest Endosc 2002;55:224-31.

127.Graziadei IW, Schwaighofer H, Koch R, et al. Long-term outcome of endoscopic treatment of biliary strictures after liver transplantation. Liver Transpl 2006;12:718-25.

128.Bourgeois N, Deviére J, Yeaton P, et al. Diagnostic and therapeutic endoscopic retrograde cholangiography after liver transplantation. Gastrointest Endosc 1995;42:527-34.

129.Kim ES, Lee BJ, Won JY, et al. Percutaneous transhepatic biliary drainage may serve as a successful rescue procedure in failed cases of endoscopic therapy for a post-living donor liver transplantation biliary stricture. Gastrointest Endosc 2009;69:38-46.

130.Kim TH, Lee SK, Han JH, et al. The role of endoscopic retrograde cholangiography for biliary stricture after adult living donor liver transplantation: technical aspect and outcome. Scand J Gastroenterol 2011;46: 188-96.

131.Pfau PR, Kochman ML, Lewis JD, et al. Endoscopic management of postoperative biliary complications in orthotopic liver transplantation. Gastrointest Endosc 2000;52:55-63. 